\title{
A identidade cigana e o efeito de "nomeação": deslocamento das representações numa teia de discursos mitológico-científicos e práticas sociais ${ }^{1}$
}

\author{
Dimitri Fazito \\ Professor do Departamento de Demografia- \\ CEDEPLAR/UFMG
}

RESUMO: Neste artigo, procura-se mostrar como a tradição cultural cigana tem sido capaz de estabelecer uma identidade dinâmica e performativa a despeito de sua complexa diversidade. Sustenta-se que o termo "cigano" é, na realidade, um estereótipo elaborado com base em representações coletivas, experimentadas por indivíduos de diferentes tradiçôes culturais ao longo de séculos de contato. O efeito de nomeação, pelo qual atores sociais posicionados assimetricamente na situação de contato inscrevem e assumem distinções (diacríticos e fronteiras) coletivas, parece fortalecer a noção de "unidade na diversidade", baseada nas experiências semelhantes de negação, diferenciação e liminaridade. Segundo uma perspectiva relacional, observase que o nomadismo cigano opera como uma representação de dupla face, resultante da fusão de discursos mitológico-científicos e práticas sociais cotidianas: de um lado, o nomadismo é o resultado aterrorizante de constantes perseguições e exílios que se inscrevem no corpo dos indivíduos e reforçam a identidade pela experiência comum da diferença; de outro, o nomadismo reforça a alteridade quando se inscreve no campo das relações interétnicas como experiência coletiva comum de deslocamento no espaço físico e social.

PALAVRAS-CHAVE: nomeação, classificação social, etnicidade, deslocamentos, nomadismo, ciganos. 
Com o passar das estaçôes e das missóes diplomáticas, Marco adestrou-se na língua tártara e em muitos idiomas de naçôes e dialetos de tribos. As suas eram as narrativas mais precisas e minuciosas que o Grande Khan podia desejar, e não havia questão ou curiosidade à qual não respondessem. Contudo, cada notícia a respeito de um lugar trazia à mente do imperador o primeiro gesto ou objeto com o qual o lugar fora apresentado por Marco. O novo dado ganhava um sentido daquele emblema e ao mesmo tempo acrescentava um novo sentido ao emblema. O império, pensou Kublai, talvez não passe de um zodíaco de fantasmas da mente.

- Quando conhecer todos os emblemas - perguntou a Marco -, conseguirei possuir o meu império, finalmente? E o veneziano:

- Não creio: nesse dia, Vossa Alteza será um emblema entre os emblemas. (Calvino, 1995)

\section{Arqueologia das representações: os ciganos e a política de nomeação}

$\mathrm{Na}$ estória de Italo Calvino (1995), Kublai Khan experimenta e imagina seu império, tendo como guia apenas as memórias e impressões comunicadas por Marco Polo, um etnógrafo onipresente e, ao mesmo tempo, um analista do inconsciente do velho conquistador. ${ }^{2}$

$\mathrm{Na}$ história dos chamados ciganos, também experimentamos e imaginamos uma tradição cultural complexa com base em representações, memórias e impressões cristalizadas em uma consciência coletiva esta o produto de disputas e dissensões no campo das relações interétni- 
Revista de Antropologia, São Paulo, USP, 2006, v. 49 no 2.

cas -, que em muito se assemelham a emblemas entre emblemas constantemente reformulados em um "zodíaco de fantasmas da mente".

Porque a imagem do "cigano" é o espelho em negativo da sociedade ocidental, sedentária e moderna, que inscreve seus diacríticos no corpo do indivíduo (e seu grupo) e, portanto, nomeia à força da opressão física e simbólica o espaço marginal destinado àqueles que perderam a luta antes mesmo de terem reconhecido sua posição no jogo (Bourdieu, 2003).

Assim, o cigano é tido e visto como selvagem - um mau selvagem, desde os primeiros contatos no Ocidente, identificado como sarraceno imoral, ignorante e herege, facínora e covarde. Na melhor das hipóteses, o estereótipo cigano negociado com o imaginário gadjo, em geral, sustenta a figura de um indivíduo indolente, bárbaro e perigoso (Hancock, 1987; Willems \& Lucassen, 1990, pp. 33-4).

Como se descobre logo em campo, chamar um kalderash (ou outro membro de qualquer categoria étnica) de "cigano" constitui uma ofensa grave e, como tal, recebemos de volta um tratamento conveniente e convencional: o kalderash "se veste" como cigano, "atua" como cigano, convence o gadjo de sua selvageria e retorna a seus afazeres cotidianos realmente sérios o mais breve possível - enfim, a encenação procede conforme as expectativas gadjé. Contudo, se não chamo o kalderash de cigano, mas de rom, ${ }^{3}$ a surpresa e curiosidade iniciais pouco a pouco dão lugar à desconfiança e a certa indiferença irritadiça: afinal, lidar com o gadjo "como cigano" ocupa menos o tempo e os sentidos do que negociar as interações "como rom".

Um aparente paradoxo, pois os roma parecem tão habituados a lidar com o estereótipo cigano e toda a violência simbólica associada a ele que, ao se depararem com novas relaçóes e representaçóes, se retraem, observam e encenam uma nova forma de convivência pouco usual depois de um difícil período no campo, de grande aversão, indiferença e estratégias de dissimulação (nos quais o que consideraríamos "mentira" 
Dimitri Fazito. A identidade Cigana E O EFeito de “nomeaÇÃo”...

constitui performance repetitiva), os roma podem se acostumar com a presença de um gadjo impertinente que, pelo menos, parece lhes reconhecer o devido grau de humanidade.

Nesse sentido, uma arqueologia conceitual do termo "cigano" é importante para revelar as interações assimétricas entre atores (individuais e coletivos) que se posicionam, relacionalmente, num campo social onde o poder de nomear e atribuir sentido é legitimado por discursos e práticas sociais elaborados de diferentes maneiras no curso da história dos contatos interétnicos.

Como sugere Pierre Bourdieu (1980a e 1980b), a consolidação das identidades (regionais e étnicas) se orienta pelas disputas em torno da classificação, isto é, do poder de "divisão" do mundo social e da nomeação dos vínculos sociais em categorias mentais (representações simbólicas) elaboradas nos discursos e nas práticas cotidianas - tanto aqueles que fazem parte do senso comum quanto os que se definem no campo especializado do saber erudito.

As representações negociadas na construção da imagem do cigano, como procuro mostrar, são fortemente determinadas pela (con)fusão do discurso erudito (ou saber científico e acadêmico) - e a prática correspondente - com o saber e a prática populares. Por conseqüência, não apenas as políticas encetadas contra aqueles denominados ciganos pela sociedade ocidental, bem como a própria organização da experiência cotidiana dos roma, são reflexos em negativo de uma identidade que emerge de um conflito desigual de longa data.

Interessante a esse respeito é a adaptação simbólica do nomadismo (efeito dos constantes deslocamentos forçados, produto de grande violência física e simbólica) ao que poderia ser uma cosmogonia pósmoderna, que atua como uma mitoprática às avessas (Sahlins, 1990). Os roma se redescobrem como filhos bastardos do Deus cristão: ouve-se uma narrativa comum daquele "cigano" ladrão, que rouba o quarto 
cravo destinado à crucificação de Jesus e depois, em franca comiseração, submete-se ao poder divino e, pela expiação dos pecados, aceita a condenação eterna de errar pela terra sem ponto de parada. $\mathrm{O}$ nomadismo torna-se mito e prática, paradoxo da punição divina e da libertação espiritual, justifica a violência real e o nome recebido, dada a assimetria no campo social. ${ }^{4}$

A contaminação entre o saber erudito e popular é palpável. Por exemplo, os verbetes de enciclopédias e dicionários clássicos da Europa iluminista, do século XVIII ao XX, foram fundamentais para a consolidação das percepções e dos estereótipos ciganos baseados no imaginário gadjo. Segundo Willems e Lucassen (1990, p. 31), "as enciclopédias desempenharam um importante papel na divulgação de certas visões sobre eles, particularmente entre as classes altas", e forneceram representações objetivas sobre os ciganos, pois eram referências legitimadas que produziram um estereótipo mais ou menos padronizado por meio da seleção editorial. Com base nessas publicações, Willems e Lucassen (id., p. 44) analisaram alguns dos termos mais freqüentes e representativos do estereótipo cigano, como bohemians, egyptians, gypsies, heathens, tsiganes e zigeuners. Todos os termos identificam indivíduos tidos por "ciganos". Porém, de acordo com cada país ou região da Europa, os termos variavam conforme as interações no contexto interétnico. Assim, segundo Jean Pierre Liégeois,

os nomes atribuídos aos ciganos são muito variados e designam, para aqueles que os empregam, realidades imprecisas e diferentes. Essas denominações nascem de uma visão míope e parcial da história dos ciganos (como é o caso na França com os chamados bohemians, nome dado aos ciganos que levavam cartas do rei da Bohemia, ou do espanhol húngaros), bem como de lendas e mitos (tal é o caso de todos os termos que procedem da palavra "Egito", como gitans, gitanos, gypsies...) e de uma terminologia empregada 
Dimitri Fazito. A identidade cigana e o efeito de “nomeaçāo”...

na língua cigana deformada (por exemplo, na França os chamados manouches e os romanichels [nos Estados Unidos]), ou de termos mais ou menos pejorativos e regionais, ligados a um aspecto físico (como os mustalainen da Finlândia - "os negros"). (1988, pp. 46-7)

A luta travada pelos atores em busca de uma identidade, segundo Bourdieu (1980b), está ligada à luta pelo controle dos critérios e das propriedades (estigmas e símbolos) da categorização. $\mathrm{O}$ discurso regional (étnico) produz e reproduz, dentro do campo de forças, uma divisão do mundo social baseada no lugar de origem dos atores e grupos na estrutura social da situação de contato.

O conhecimento e reconhecimento da origem e da divisão do mundo em categorias sociais delimitadas constituem aquilo que Bourdieu qualifica de um ato mágico, ou seja, a transformação de uma "continuidade natural" em fato social discreto (o espaço geográfico se torna espaço social, território político), separando-o em categorias distintas de classificação que retêm um poder específico no campo de forças. Os grupos tentam o monopólio do poder de fazer ver e crer, o poder de impor sua própria classificação e o poder de dominar o mercado de bens simbólicos - ou seja, o domínio das imagens e dos estereótipos.

No caso dos "ciganos", encontramos um discurso "classificatório" das pessoas e dos grupos em categorias separadas (ciganos e não-ciganos, hereges e cristãos, primitivos e modernos), que orienta o conjunto das práticas discriminatórias violentas contra os peripatéticos. Portanto, a tradição cultural roma não pode ser dissociada do transcurso histórico que relaciona também um saber (discurso) científico e mitológico (Bourdieu, 1980a), elaborado sobre as impressões convergentes de distintas e incontáveis situações paralelas de contato.

Tais impressões convergentes podem ser identificadas como imagens exóticas, freqüentemente caracterizadas por atributos negativos, como 
o cigano herege (heathens) ou nômade. Assim, por exemplo, Piasere e Campigotto (1990) analisaram as transformaçôes das imagens sobre os ciganos a partir da literatura renascentista italiana, apontando as personagens emblemáticas de Margutte e Cingar, indivíduos amorais, selvagens e infiéis que se fundiram à personagem exótica e ambígua do cigano no século XVI.

Com base nas análises de Bourdieu (1980a, pp. 21-5) sobre a Teoria dos Climas de Montesquieu, podemos proceder a uma arqueologia das imagens do "cigano", elaboradas a partir de sua chegada à Europa, e identificar como ocorre o processo de fusão entre o discurso científico e mitológico sobre as origens e características de uma tradição cultural singular, porém internamente fragmentada à semelhança de um mosaico multicultural.

Quando Montesquieu pergunta se "a diferença entre os climas onde os homens nascem contribui para a diferença entre seus espíritos”, tenta justificar as diferenças morais (do caráter e do comportamento) entre os habitantes de determinadas regiões da França, baseado em considerações preconceituosas que sustentam a influência geoclimática na constituição social dos homens (id., p. 21).

Segundo Bourdieu, essa seria uma teoria bem-sucedida quanto à justificação das diferenças regionais na formação da identidade de grupos e indivíduos, pois Montesquieu teria formulado uma teoria científica com base em elementos míticos que se encontravam estabelecidos previamente no imaginário popular, incorporados nas tradições locais. Assim, sua concepção teórica da influência climática, geográfica e demográfica (fatores naturais) sobre a formação do caráter humano fora formulada a partir da crença do pensamento comum e cotidiano, preconceituoso, regionalizado e mitificado, e posteriormente mesclado ao pensamento iluminista, científico e racionalista, próprio de sua época. 
Dimitri Fazito. A identidade cigana e o efeito de “nomeaçāo”...

Segundo Bourdieu,

a Teoria dos Climas é, de fato, um paradigma da mitologia "cientifica", discurso fundado na crença (ou no preconceito) sobre a ciência e que se caracteriza então pela coexistência de dois princípios de coerência conjugados: uma coerência proclamada, do desenvolvimento científico que se afirma pela multiplicação dos signos exteriores da cientificidade, e uma coerência camuflada, mítica em seu princípio. (ibid.)

As diferenças culturais, categorizações e preconceitos locais seriam justificados coerentemente dentro do discurso mitológico, caracterizado no pensamento comum e cotidiano por oposiçóes binárias elementares.

Em Montesquieu, essas coerências simbólicas de natureza mitológica se fundem ao discurso científico de tal modo que as diferenças se tornam "legítimas" e passam a ser utilizadas como instrumentos de distinção (segregação) e de dominação justificadas. À coerência científica proclamada, racional e objetiva, mistura-se clandestinamente a coerência mítica camuflada, obscura e ambígua. As relaçôes de poder em torno desse discurso (mitológico-científico) ficam mais claras à medida que Montesquieu apresenta suas conclusões sobre a constituição dos Estados e das leis do espírito que governam as ações e instituiçoos humanas.

De acordo com sua concepção científica, aqueles que procedem do norte são fortes, vigorosos, intelectualmente privilegiados e senhores (nasceram para a conquista e a dominação); de outro lado, aqueles que procedem do sul são fracos, sensíveis (no sentido pejorativo, efeminados), indolentes, brutos (selvagens) e escravos (nasceram fracos e servis). Nesse discurso, em que ciência e mito se fundem, opõem-se senhores e escravos, dominadores e dominados, o masculino e o feminino, o forte e o fraco, o frio e o calor, a potência e a impotência, o norte e o sul. ${ }^{5}$ 
Bourdieu nos mostra então como o discurso e as práticas cotidianas populares, eminentemente localistas e regidas por uma mito-lógica inscrita na tradição, fundem-se ao discurso e às práticas eruditas, próprias do projeto científico iluminista.

No caso de Montesquieu, a coerência mítica, definida pelas oposições binárias características do pensamento comum, acaba se legitimando dentro do discurso científico e justifica, conseqüentemente, as relaçóes assimétricas e estigmatizantes entre habitantes do norte e do sul. As representaçōes sobre as culturas e suas diferenças, dessa forma, são legitimadas e organizadas em um campo social que estabelece o teor das interações entre atores portadores de identidades e emblemas distintos.

\section{Discursos científicos, mitos e perseguições}

Desde as mais remotas origens, a história dos ciganos é marcada pela sobreposição e pelo deslocamento constante de representaçôes sociais diversas, que são produto de uma confluência de discursos mitológicocientíficos e práticas cotidianas num campo de forças assimétricas.

Assim, a história "oficial" (do ponto de vista do Outro, do não-cigano) é essencialmente "mítica", misturando perspectivas discursivas diversas e ambíguas que, ao final, nos contam mais sobre a história não registrada do Velho Mundo do que sobre a história dos ciganos propriamente ditos. ${ }^{6}$ Pois, do ponto de vista da cultura ocidental, a história cigana é fundamentalmente efeito de "nomeação", aquilo que se atribui ao $\mathrm{Ou}$ tro descolado de toda a interação e disputa anterior efetiva, ou seja, efeito do espelho em negativo daquilo que se quer negar sobre si mesmo.

Segundo Angus Fraser (1995), os ciganos teriam chegado a Constantinopla por volta do ano 1000 d.C., sendo chamados de adsincani, um grupo de mágicos e feiticeiros viajantes, "notórios pelas predições e 
Dimitri Fazito. A identidade Cigana E O EFeito de “nomeaÇÃo”...

feitiçaria" que praticavam. Mais tarde constata-se a utilização do termo grego atsinganoi ou atzinganoi, que denomina grupos de feiticeiros e "leitores da sorte" (fortune-telling). É importante destacar que estes últimos termos parecem ser uma corrupção lingüística do termo athinganoi, o nome de uma antiga seita herética grega (id., p. 46).

Esses grupos de viajantes se fixam na região do Peloponeso, na Grécia, no início do século XII, e a partir daí aparecem vários testemunhos indicando sua presença por meio da descrição de monges cristãos em peregrinação à Terra Santa e de outros nobres senhores donos de terras (id., pp. 47-50; Liègeois, 1988, pp. 35-9).

Talvez o fato mais importante para a história dos ciganos tenha ocorrido na fixação de alguns grupos numa região grega denominada Pequeno Egito (ou monte Gyppe). Posteriormente, ao longo do século XV, muitos ciganos que chegam a solo ocidental passam a afirmar sua proveniência do Pequeno Egito, que freqüentemente seria confundido pelos europeus com o próprio Egito. Os nomes gypsies (inglês), gitanos (espanhol), gitan (francês), zingari (italiano), zigeuner (alemão) e ciganos atestam essa relação e essa representação fundamental sobre grupos etnicamente distintos.

No final da Idade Média, principalmente a Europa ocidental parecia se debater entre uma forma de "renovação cultural e tecnológica" e a consolidação de antigas instituições e valores morais - período de grandes descobrimentos e revoluçôes, mas também de grandes perseguições e catástrofes. Em meio a tudo isso, a presença dos ciganos se mostrava de maneira delicada.

Em um primeiro momento, eles foram recebidos com certo entusiasmo e curiosidade, pois eram indivíduos exóticos, provenientes de terras distantes, que aguçavam a imaginação do povo em geral e dos intelectuais. Contudo, não demorou muito para que fossem identificados com a bruxaria, o paganismo e o banditismo. Logo, os rumores e boatos sobre 
a origem herética e selvagem desses peregrinos se difundiram pelos quatro cantos da Europa, fundamentando os primeiros estereótipos sobre os ciganos.

Segundo Piasere e Campigotto (1990, p. 18), por volta de 1500, os aspectos exóticos ou bizarros associados aos ciganos são intensificados pelos perigos sociais: "uma vez que a curiosidade levantada pelos ciganos desaparece e suas cartas e salvo-condutos para peregrinação perdem credibilidade, eles passam a ser tratados como vagabundos”. Somam-se assim aos muitos erranti (andarilhos), associados aos mendigos, resultantes da crise econômica. Tornam-se desterrados, aqueles que não podem voltar para seu lugar de origem, refugiados ou escorraçados em geral, contra os quais se fazem freqüentes os banimentos e as perseguições com a ordem de salvaguardar a saúde pública e manter a paz.

Assim, muito rapidamente, a repulsa aos ciganos na Europa ocidental se tornou um fato constante. Podemos ver, principalmente por meio das crônicas e dos depoimentos veiculados por jornais e diários populares de fins do século XV, a difusão entre (e pela) população das imagens negativas sobre os ciganos. Liégeois nos apresenta um cronista do século XV que escreve, no Diário de um burguês em Paris, que os recémchegados ciganos

[...] eram os mais pobres seres que jamais haviam chegado à França, segundo se recorda. E, apesar de sua pobreza, seguiam em sua companhia as bruxas que olhavam as mãos das pessoas e que diziam o que havia acontecido ou o que iria acontecer [...]. E o pior era que, falando das criaturas, por arte da magia ou de outro modo, pelo inimigo do inferno ou por artimanhas e outras habilidades, esvaziavam as bolsas das pessoas e enchiam as suas, segundo se dizia. A bem da verdade, estive lá três ou quatro vezes para lhes falar, porém nunca me dei conta de haver perdido um só centavo, nem os vi lerem as mãos, mas assim diziam por todas as partes [...]. Afinal, tiveram 
Dimitri Fazito. A identidade cigana e o efeito de “nomeaçāo”...

de ir embora, e partiram no dia de Nossa Senhora, em setembro, seguindo para Pontoise. (Liégeois, 1988, p. 43, grifos meus)

Também quando chegaram à Itália foram bem recebidos inicialmente, adquirindo salvo-condutos do Papa em Roma, que os permitiu vagar pelas províncias italianas. Mas logo os cronistas locais começaram a descrevê-los como "a raça mais horrorosa jamais vista" até então, "negros e magros que comem como porcos". Teriam cometido tantos furtos de maneira tão vulgar que logo ganharam fama de perigosos ladrões e selvagens (Piasere \& Campigotto, 1990, p. 15).

Numa das crônicas da época, a Cronaca Fermana, é relatada a chegada a Fermo, em 1430, "de certas pessoas conhecidas como zengari [...] elas tinham privilégios papais e imperiais [...] e eram pessoas muito vis que tentavam defraudar e iludir qualquer pessoa que pudessem. Diziam ser quiromantes e, quando podiam, roubavam tudo de uma só vez" (ibid.).

Nesses breves relatos, podemos ver como as primeiras representaçôes sobre os ciganos se organizavam dentro do imaginário popular que alimentava as diversas crônicas e os depoimentos em jornais. Vários documentos da época mostravam as impressões do povo em relação aos ciganos. Na realidade, pouco se sabia sobre esses "seres excêntricos" que vinham de terras distantes. Apenas o que era dito ou comentado parecia ser suficiente para preencher as curiosidades e fantasias da população - afinal, "o que se dizia por todas as partes" sobre os ciganos era o que importava.

Para Donald Kenrick e Grattan Puxon (1972, p. 19), aparentemente, o ódio e os preconceitos em relação aos ciganos na Europa atual são reflexos da memória e de folclores populares relativos às primeiras impressões sobre eles ainda na Idade Média. A "convicção de que a negritude denotava inferioridade e perversidade [associada aos mouros e aos chamados sarracenos] estava bem sedimentada na mentalidade 
Revista de Antropologia, São Paulo, USP, 2006, v. 49 no 2.

ocidental. A pele quase negra de muitos ciganos condenou-os a serem vítimas do preconceito".

A condenação moral dos ciganos como indivíduos perversos, hereges e selvagens e, conseqüentemente, a suposição de banditismo, violência e vagabundagem tomaram contornos definitivos ao longo dos séculos XVI e XVII, graças à incorporação dessas representações populares sobre os ciganos na literatura e nas caracterizações artísticas do início da Idade Moderna.

Inicialmente, as personagens ciganas surgiram nas narrativas fantásticas e satíricas de literatos e intelectuais do período renascentista, sofisticando-se posteriormente nos romances picarescos do século XVII.

Por exemplo, Piasere e Campigotto estudam a arqueologia de uma imagem genérica dos ciganos no período renascentista italiano e sua incorporação literária nos poemas do ciclo carolíngeo, de autoria de Luigi Pulci e Teofilo Folengo. Segundo esses pesquisadores, as duas personagens principais das histórias, Margutte e Cingar "são representaçôes de dois momentos emblemáticos da passagem da figura literária do Sarraceno/Egípcio/Pagão para a figura do Cingaro (cigano), que toma lugar na virada do século XV” (Piasere \& Campigotto, 1990, p. 15). As personagens Margutte e Cingar representam o protótipo do indivíduo amoral, ambíguo e anti-social. Tentam a todo momento serem "normais", mas sempre em vão, dada sua natureza monstruosa e néscia.

Margutte, personagem dos poemas de Luigi Pulci, incorpora as características do Sarraceno, estrangeiro pagão que tenta se aproveitar da boa índole das pessoas, enfim, um facínora incorrigível. Segundo Piasere e Campigotto, no caso de Cingar, a personagem dos poemas de Teofilo Folengo, existe uma representação mais profunda de determinadas atitudes relativas às camadas sociais da população. Cingar é, na realidade, a fusão de atributos opostos: uma fantasia intelectual - o desejo de liberdade de expressão e aquisição do conhecimento - e uma situação social 
Dimitri Fazito. A identidade cigana e o efeito de “nomeaÇĀo”...

instável - o indivíduo excêntrico, viajante e aventureiro, plebeu sem propriedades (à exceção do suposto conhecimento).

Assim, Cingar representa a ambigüidade moral e intelectual da sociedade renascentista: como "Margutte é um degenerado Sarraceno, Cingar é um degenerado Cristão, com a diferença de que o último é também um astrólogo. [...] O banimento de Cingar significa também o banimento de um intelectual que se recusa a aceitar as hierarquias sociais de seu tempo" (id., pp. 23-4). ${ }^{7}$

As representações sobre os ciganos continuaram nos romances picarescos dos séculos XVII e XVIII e, mais recentemente, nos romances do período romântico do século XIX, revelando novos atributos e redefinindo outros. A representação do cigano passa a incorporar de vez a imagem do indivíduo anti-social e amoral ao mesmo tempo em que representa romanticamente o aventureiro, amante inveterado e boêmio.

Em 1773, Goethe encontra na figura do cigano a encarnação do nobre selvagem, contrastando-o com os aspectos materiais e fugazes da vida cotidiana, perfeitamente de acordo com os preceitos românticos e liberais do iluminismo alemão. Mas, segundo Fraser,

de acordo com outros [escritores], convenções mais depreciativas se espalharam no século XIX, apresentando os ciganos como selvagens e marginais que se entregavam ao sobrenatural, ao misterioso e ao crime: eles podiam ser usados em livros para crianças ou adultos, como uma estratégia de construção do roteiro, explicando roubos, estranhos acontecimentos ou eventos ocultos ou (seguindo uma história precedente de Cervantes em $\mathrm{La}$ Gitanilla e depois Moll Flanders de Defoe) o relato do desaparecimento de crianças roubadas de seus pais. $(1995$, p. 197)

Escritores como Gil Vicente, Cervantes, Henry Fielding, Daniel Defoe, Goethe e, posteriormente, Victor Hugo sintetizaram as diversas 
imagens - principalmente negativas, por vezes romantizadas - encontradas nas histórias e nos provérbios populares, e ainda ajudaram a difundir outras imagens um tanto equivocadas sobre os ciganos.

Contudo, as imagens sobre os ciganos não foram difundidas e cristalizadas no imaginário popular apenas pelos depoimentos de cronistas e jornalistas, ou pelas histórias e narrativas construídas pelos escritores da época. Muitas das representações coletivas que fundamentam as relaçôes entre ciganos e não-ciganos, atualmente, foram elaboradas a partir dos discursos acadêmicos e científicos desenvolvidos desde o período renascentista.

Voltamos aqui ao problema inicial proposto na análise de Bourdieu sobre a Teoria dos Climas de Montesquieu. Isto é, o que podemos constatar na nascente ciganologia e em seus desdobramentos é a fundamentação de um discurso mitológico-científico, que incorpora representações próprias do senso comum (os mitos e as lendas sobre as origens e a constituição moral dos indivíduos identificados como ciganos) às representações científicas (explicações objetivas, disciplina moral e, supostamente, a neutralidade axiológica na análise da cultura e história dos chamados ciganos), criando uma espécie de "justificativa racional” para os preconceitos e estereótipos "inventados" e assimilados historicamente pelo senso comum em geral.

Traçando o perfil das análises feitas por filósofos, cientistas, intelectuais e acadêmicos sobre os ciganos, podemos constatar a falta de dados etnográficos fidedignos e outros de primeira mão, que só irão surgir no cenário da ciganologia a partir da década de 1970 .

Os primeiros intelectuais e cientistas a falar sobre os ciganos foram os filósofos, lingüistas e historiadores que muitas vezes se confundiam com aventureiros, missionários ou viajantes a serviço da Igreja ou dos Estados coloniais e que, na maior parte das vezes, nunca haviam sequer visto um cigano. 
Dimitri Fazito. A identidade cigana e o efeito de “nomeaçāo”...

As informações colhidas sobre os ciganos baseavam-se em geral nas crônicas e nos depoimentos antigos. Desse modo, em 1751, encontramos na Enciclopédia de Diderot uma representação sobre os ciganos já amplamente aceita entre a população. Ali, os ciganos são definidos como "vagabundos que professam ler a sorte através da leitura das mãos. Seu talento está em cantar, dançar e roubar" (in Fraser, 1995, p. 147). Nada além das imagens já cristalizadas no imaginário comum, só que desta vez sustentadas por um intelectual da vanguarda do projeto iluminista.

As opiniōes expressas nas enciclopédias e nos dicionários nos informam a respeito das representações sobre os ciganos, já que aquelas eram as principais formas de divulgação do conhecimento a partir do século XVIII - especialmente o conhecimento burguês, isto é, o conhecimento legítimo - entre os homens cultos, autoridades e políticos e, finalmente, entre aqueles das classes menos favorecidas que começavam a ter acesso a um sistema de educação formal.

Segundo Willems e Lucassen (1990, pp. 34-5), constantemente, os ciganos eram apresentados nas enciclopédias como preguiçosos por natureza, e "só trabalharão quando forçados por extrema necessidade". "Não lhes falta inteligência, mas dada sua educação e baixa moralidade, este atributo geralmente se transforma em malícia." E, "porque os ciganos (geralmente) não têm noções de moralidade, permitem que seus instintos os regulem facilmente, pois não têm senso de honradez, são insaciáveis [...] e frívolos". "Conseqüentemente os ciganos são rudes e selvagens", sem qualquer noção de civilidade, são freqüentemente desleais e desonestos, cruéis, mas ao mesmo tempo covardes e insensíveis.

Um bom exemplo da difusão dessas imagens deterioradas está em uma enciclopédia cristã, editada na Holanda em 1886, na qual se afirmava que, "embora os ciganos tivessem vivido entre cristãos durante séculos, não tinham eles abandonado seu paganismo, pelo que permaneciam rudes e selvagens, presos a uma existência nômade [...]” (id., p. 34). 
No entanto, a consolidação das representaçôes dentro do discurso científico (ou melhor, mitológico-científico) não se deu apenas por meio dos trabalhos de intelectuais apresentados nas enciclopédias e nos dicionários. Boa parte do material utilizado na confecção dos textos e nas definiçôes dos verbetes enciclopédicos baseava-se largamente em algumas poucas, mas importantes, produçôes e pesquisas dos primeiros ciganólogos. Especial atenção merecem Heinrich Grellmann (1753-1804), filósofo, lingüista e historiador alemão, e George Borrow (1803-1881), tradutor e bibliotecário inglês. ${ }^{9}$

Ambos produziram trabalhos que se tornaram sucesso editorial, e muitos dos estereótipos elaborados em suas análises permanecem até hoje, não só entre o senso comum, mas também entre alguns ciganólogos contemporâneos.

Em 1783, Grellmann escreveu Die Zigeuner (Os ciganos), que se tornou best seller, sendo traduzido para várias línguas imediatamente. Ali, Grellmann apresentou as principais teorias sobre os ciganos conhecidas até então, reforçando-as ou criando novas representaçôes. E, embora Grellmann não tenha sido o primeiro intelectual a escrever livros sobre ciganos, certamente foi o primeiro a produzir uma obra de grande impacto, bastante sistemática e padronizada sobre o assunto, além de sintetizar boa parte das representaçôes sobre os ciganos existentes na época.

"Além da originalidade de seu trabalho, sua importância reside no fato de ter compilado e popularizado diferentes tipos de estereótipos. Podemos comprovar esse fato, pois as muitas opiniôes sobre os ciganos formuladas posteriormente ainda são encontradas nas formas rudimentares ou ampliadas em seu livro" (Willems \& Lucassen, 1990, p. 42). Por exemplo, a idéia do suposto canibalismo praticado pelos ciganos tem sua primeira aparição em um trabalho "científico" no livro de Grellmann. Segundo Fraser, 
Dimitri Fazito. A identidade cigana e o efeito de “nomeaÇÃo”...

Grellmann estabeleceu os padrões para os subseqüentes pesquisadores ao longo de muitos anos. Ele também ampliou e difundiu vários temas sensacionalistas como a irrestrita depravação das mulheres ciganas e as acusações de canibalismo. Quanto a isso, ele deu crédito considerável aos comentários absurdos de jornais húngaros e alemães envolvendo mais de 150 ciganos, 41 dos quais, depois de confissōes extraídas sob tortura, foram executados pelos mais variados métodos devido a crimes que incluíam o [suposto] canibalismo. (1995, pp. 195-6) ${ }^{10}$

Porém, a contribuição mais importante de Grellmann ao desenvolvimento da ciganologia foi sua teoria lingüística da origem indiana dos ciganos, que permanece até hoje, tendo sida corroborada por estudos lingüísticos contemporâneos.

Grellmann fundamentou sua noção da ascendência indiana dos ciganos atuais em dois fatores: o primeiro, compreendendo os estudos lingüísticos comparativos que, de acordo com Grellman, indicavam uma grande afinidade entre a língua romani dos ciganos e as línguas derivadas do hindustani. $\mathrm{O}$ segundo fator se baseia nos relatos de viajantes lidos por Grellmann, que davam conta da existência de uma casta de párias [...], dos quais a cor, a forma, o caráter, a moral e os costumes apresentavam muitas semelhanças com as imagens que ele tinha dos ciganos e de seu modo de vida. (Willems \& Lucassen, 1990, p. 33)

As suposições de Grellman a respeito da origem indiana dos ciganos, embora corretas, contribuíram para a invenção de outros estereótipos apresentados sutilmente por meio do discurso científico, montado sobre as teorias e os conceitos dos nascentes estudos lingüísticos.

Pela primeira vez encontramos a caracterização étnica dos ciganos, ou ao menos a idéia de que estes possuíam uma tradição cultural singu- 
lar e autônoma, já que a descoberta de um lar localizado na região centro-oeste do território indiano "não deixava dúvidas" quanto à sua herança cultural.

Até então, muitos intelectuais e autoridades públicas supunham que os ciganos na realidade faziam parte de uma classe de seres degenerados socialmente, misturados a mendigos, vagabundos, pequenos ladrões, loucos e tantos outros marginais sociais produzidos pela sociedade medieval e pré-capitalista.

As teses de Grellmann derrubaram um mito mas criaram outro. Se os ciganos compunham um grupo cultural original da Índia, o que importava era o fato de constituirem desde o princípio uma raça de degenerados. Por isso, segundo Grellmann, assemelhavam-se tanto aos párias da sociedade indiana.

"Uma pele escura, baixa estatura, crianças nuas, moradia em tendas, preferência por roupas encarnadas, uma língua secreta, danças sensuais, endogamia; indivíduos sujos e horrorosos, medrosos e covardes, ladrões, mentirosos, sem noção do pecado [...], as mulheres tinham uma conduta imoral [...]." Além disso, possuíam uma cultura material pobre, tendo de viver em cavernas ou habitações primitivas junto de animais selvagens. Assim, de indivíduos pertencentes às classes baixas, tornaram-se indivíduos racialmente degenerados, justificando a assimilação ou o extermínio desses grupos estranhos (Moonen, 1996, pp. 31-2).

Posteriormente, nos séculos XIX e XX, George Borrow e vários outros ciganólogos contribuíram para a difusão de idéias e imagens equivocadas sobre os ciganos. ${ }^{11}$ Borrow, que também escreveu best sellers como The Bible in Spain (1843) e Lavrengo (1851) -, elaborou muitos dos mitos conhecidos sobre os ciganos hoje em dia, acusando-os de prática de canibalismo, rapto de crianças, utilização de seus conhecimentos de medicina (curandeirismo) e feitiçaria para envenenamentos de animais e pessoas, heresia e furtos. ${ }^{12}$ 
Dimitri Fazito. A identidade cigana e o efeito de “nomeaçāo”...

O ponto a ser destacado, no entanto, é a fusão do discurso científico com o discurso mitológico, como ficou evidenciado acima. Sob a pretensa objetividade científica, os mais absurdos e preconceituosos relatos e histórias populares foram confirmados e legitimados. Esses ciganólogos, ao fundirem o conhecimento comum ao científico, deram a justificativa necessária aos governantes e às pessoas em geral para que pusessem em prática, sem conflitos éticos ou morais, suas políticas racistas e seus comportamentos discriminatórios em relação aos ciganos.

Freqüentemente subestimamos a importância dessas representações para a construção da identidade etnicizada dos ciganos. Podemos ver como, ao longo dos séculos posteriores à chegada dos primeiros ciganos à Europa ocidental, as representações vão se definindo cada vez mais negativamente.

As representações do senso comum - o cigano como indivíduo amoral, infiel, violento e exótico - são logo adaptadas ao discurso literário, e depois ao discurso científico, formando o substrato para novas imagens e atributos: ciganos representados como indivíduos anti-sociais, desonestos, ardilosos e parasitas sociais. A essas representações se fundem, em um dado momento do século XVI, as representações elaboradas pelas autoridades públicas e pelos governantes em geral, que, sob o argumento de "protegerem a ordem e saúde pública", implementam as primeiras políticas persecutórias em relação aos ciganos - eles serão perseguidos simplesmente por serem ciganos. Considerados, inicialmente, vagabundos, avessos ao trabalho, exploradores da boa-fé e ladrões violentos e perigosos com suas bruxarias, e, posteriormente, indivíduos racialmente impuros e degenerados, tornou-se possível a plena justificação das perseguições e expulsões, a assimilação ou o extermínio desses indivíduos indesejáveis pelas autoridades públicas.

Em princípio, os ciganos sofreram punições como banimentos e expulsão dos territórios por que passavam e nos quais tentavam se fixar. 
Mas, com o agravamento das relaçôes entre a população em geral e os ciganos e, ainda, com a cristalização das representações no imaginário popular, a impaciência das autoridades públicas se tornou cada vez maior, e como resultado intensificaram-se as punições no sentido da assimilação ou do extermínio completo dos grupos e indivíduos.

Em algumas regiōes do Leste europeu, como na Moldávia e Transilvânia, ciganos roma foram escravizados por 500 anos, forçados ao trabalho, negociados como mercadoria entre os senhores feudais e extirpados de toda forma de propriedade (Fraser, 1995, pp. 223-6; Hancock, 1987). Segundo a descrição do reformador e abolicionista romeno Kogalniceanu, pelas ruas se viam

[...] seres humanos acorrentados pelos braços e pernas, outros com grilhōes de ferro nas cabeças e outros ainda com coleiras de metal ao redor dos pescoços. Eram punidos cruelmente, seja pela fome, pelo confinamento solitário ou sendo jogados nus na neve ou em um rio congelado [...]. Da santidade do casamento e dos laços familiares eram feitas zombarias: a esposa era separada de seu marido, [...] as crianças tomadas da mãe e vendidas como gado a diferentes compradores pelos quatro cantos da Romênia. (in Fraser, 1995, p. 224)

$\mathrm{Na}$ Europa ocidental, a despeito da escravidão não ter sido instituída, nenhum tratamento melhor foi destinado aos ciganos. Fraser (id., p. 92), por exemplo, comenta que em 1530 em Baden, na Alemanha, "ciganos vagavam em todo lugar, e as autoridades locais ordenaram que não se permitisse a fixação deles, alertando-os que seriam enforcados caso fossem pegos defraudando as pessoas. [...] quando encontrados, deveriam ser presos e punidos de acordo com a lei, se encontrados na fronteira, deveriam ser banidos". Casos como esse eram freqüentes em toda a Europa, e não raro alguns países e principados se organizavam 
Dimitri Fazito. A identidade Cigana E O EFeito de “nomeaÇÃo”...

em "caçadas" aos ciganos, promovendo sua expulsão ou mesmo sua execução (Liégeois, 1988).

$\mathrm{Na}$ Espanha e em Portugal, os ciganos eram freqüentemente condenados às galés, ou então degredados para as colônias de além-mar. Por exemplo, em Portugal, a provisão de 17 de junho de 1694 declarava que "todos os que tiverem entrado neste Reino saiam dele em termo de dois meses, com pena de morte, e, passados o dito termo, serão havidos e banidos e se praticará com eles a pena de banimento na forma da lei". E ainda, em último caso, seriam todos os ciganos obrigados a "seguirem para as conquistas da África ou das Índias” (Pieroni, 1993, p. 120). Conseqüentemente, os primeiros ciganos a aportarem no Brasil expressam o efeito da aplicação de políticas persecutórias de Portugal. Em sua maioria Calons (matriz étnica dos ciganos ibéricos), que de uma forma ou de outra contribuíram para o povoamento das áreas mais inóspitas do território, constituindo-se ainda como mão-de-obra barata, dedicados especialmente ao mercado paralelo de escravos (Donovan, 1992, p. 36).

Várias tentativas também foram feitas no sentido de assimilar ou exterminar a "raça" cigana, pois, sendo ela uma "raça degenerada", poderia haver duas formas de combate: assimilar seus indivíduos, diluindo seus traços genéticos e seus costumes entre a população "saudável”; ou o extermínio completo, eliminando tanto sua cultura quanto sua herança genética. A primeira forma possui exemplos antigos e modernos: de um lado, a tentativa da rainha Maria Teresa da Áustria no século XVIII e, mais tarde, já no século XX, o grande projeto assimilacionista das minorias étnicas nos países socialistas do Leste europeu (Liégeois, 1987; Hancock, 1987; Crowe, 1995; Stewart, 1997).

Segundo Jean-Pierre Liégeois, 
[...] Maria Teresa, depois de reprimir violentamente os ciganos, mudou sua política completamente em 1758, através de uma série de decretos. Primeiro, ela forçou todos os ciganos a venderem seus cavalos e caravanas, enquanto os grandes donos de terra tiveram de dar-lhes terras e materiais para que construíssem suas casas. O resultado foi o confinamento dos ciganos, aos quais não era permitido transitarem além de suas vilas sem autorização escrita. Ela, então, baniu o uso do termo Cigány, que foi substituído por "novo cidadão" [...]. Em 1767, proibiu o tradicional voivoda (chefe) de manter julgamentos sobre seu grupo; os grupos familiares passaram a se sujeitar às magistraturas locais, e gradualmente se desintegraram. Viagens, vestimentas, linguagem, alimentação e comércio praticados foram controlados, e os infratores das novas normas eram então punidos. De 1773 em diante, os casamentos entre ciganos foram proibidos e, a cada casamento inter-racial, eram conferidos 50 florins. Aos 5 anos de idade, as crianças ciganas eram tomadas de seus pais e doadas às famílias camponesas a fim de que pudessem educá-las. (1987, p. 99)

Já no século XX, nos países socialistas do Leste europeu, as políticas de assimilação visaram, sobretudo, a unificação ideológica das minorias étnicas às classes trabalhadoras.

Os comunistas viam os ciganos como membros do lumpemproletariado e, portanto, opositores potenciais às mudanças socialistas da sociedade. A tarefa, conseqüentemente, era "criá-los" entre as classes trabalhadoras, nas fábricas. Lá, a disciplina, a organização e o espírito de coletividade da linha de produção socialista proveriam os ciganos com o modelo básico a ser utilizado não em seu trabalho, mas em todos os aspectos de suas vidas. (Stewart, 1997, p. 85) ${ }^{13}$ 
Dimitri Fazito. A identidade Cigana E O EFeito de “nomeaÇÃo”...

Mas tais políticas não tiveram êxito, já que os ciganos sempre foram tratados como trabalhadores de segunda classe, sem merecer muita confiança das pessoas. $\mathrm{O}$ passado e as representaçôes não podiam ser assimilados ou eliminados da memória (e das açōes).

Contudo, as piores políticas empreendidas foram sem dúvida aquelas que buscaram o completo extermínio dos ciganos, exemplificado classicamente pelas políticas da Alemanha nazista.

Em 1899 foi criado em Munique o Bureau Central para Luta Contra a Perturbação Cigana, o qual não havia sido fechado oficialmente até 1970 (Hancock, 1987, p. 61). Apoiadas nas antigas teorias e nos estereótipos desenvolvidos nos trabalhos de Grellmann e Leibich e, posteriormente, nos estudos da antropologia física e criminologia - como podem ser atestados pelos trabalhos de Lombroso sobre os ciganos -, ${ }^{14}$ as autoridades alemãs se convenceram da árdua tarefa de exterminação da "raça" cigana.

Já nos primeiros dias do governo nazista, segundo Ian Hancock (1987, p. 62), "um estudo de um grupo SS sugeria que todos os ciganos presentes na Alemanha deveriam ser mortos por afogamento, conduzindo-os para navios que, em alto-mar, seriam afundados". Hancock faz notar também que as políticas anti-semitas ainda não haviam sido implementadas.

Mais tarde, autoridades do recém-criado Centro de Pesquisa para Higiene Racial e Biológica da População, em Berlin, iniciaram seus estudos sobre os ciganos, codificando as pessoas de origem romani por meio da elaboração de genealogias.

Kenrick e Puxon (1972), analisando as aplicaçôes das leis nazistas sobre ciganos e judeus, descobriram mais tarde que o critério utilizado pelos alemães para a classificação da herança cigana era duas vezes mais estrito que o utilizado para a classificação dos judeus. ${ }^{15}$ Vinte mil ciganos poderiam ter sido salvos se os mesmos critérios aplicados aos judeus 
fossem usados para os ciganos. No entanto, aproximadamente um terço da população cigana européia (especialmente, alemã) foi exterminada nos campos de concentração nazista.

Em 1933, bem antes dos judeus, as mulheres ciganas começaram a ser esterilizadas. Em 1938,

uma proclamação do Partido Nazista afirmava que o problema cigano era categoricamente um problema racial e deveria ser cuidado à luz dessa noção; um ano depois, Johannes Behrendt, falando pelo partido, declarou que a "eliminaçãoo sem hesitação" de toda a população cigana deveria ser promovida imediatamente, embora algumas famílias devessem ser estocadas em algum depósito para que, no futuro, antropólogos pudessem estudálas. (Hancock, 1987, p. 65)

Depois da Segunda Guerra Mundial, muitos ciganos haviam sido mortos mas, mesmo assim, algumas políticas desastrosas continuaram sendo empregadas em diversos países como Inglaterra, Holanda, Alemanha e França. Sob o pretexto de se utilizarem estudos e métodos científicos no "controle" dos grupos ciganos, apoiados em grupos de cientistas sociais, médicos, psicólogos e assistentes sociais, muitas autoridades públicas continuaram e ainda continuam tratando os ciganos discriminatoriamente.

Os preconceitos, as imagens e as histórias "inventadas" cotidianamente pelo senso comum são freqüentemente legitimados por determinados discursos científicos - ou pretensamente científicos -, fundindo-se e se confundindo com estes.

Como na Teoria dos Climas de Montesquieu, diferenças culturais são justificadas "objetivamente" pelas leis naturais. A diferença cultural em relação aos ciganos, depois de naturalizada, torna-se passível de tratamento, correção e extermínio. A "imoralidade" e "impureza” ciganas 
podem ser explicadas cientificamente pela biologia, antropologia ou psicologia e, posteriormente, corrigidas e adaptadas aos padrões considerados "normais", "saudáveis", "puros" e "dominantes".

Enfim, o discurso mitológico-científico tem o poder de dividir socialmente o mundo, legitimando algumas representações e imagens, condenando outras e fundamentando práticas cotidianas. Utilizado como recurso para o estabelecimento de estratégias e políticas públicas, o discurso mitológico-científico da ciganologia contribuiu, em alguma medida, para a consolidação das perseguiçôes aos ciganos e exclusões deles, além da cristalização e manutenção de muitas de suas imagens deterioradas.

\section{Traficando mitos e representações: o nomadismo como operador das diferenças}

Em seu estudo pioneiro, Thomas Acton (1974) analisou diversos preconceitos de ciganólogos contra alguns ciganos e o senso comum em geral que fundamentavam a crença em um "cigano de sangue verdadeiro" (true blooded gypsy). Para Acton, ele mesmo um sociólogo de origem roma,

a maior falha da literatura sobre os ciganos, tanto a oficial quanto a acadêmica, é a supergeneralização; os observadores foram facilmente levados a acreditar que práticas particulares de um grupo são universais, com a conseqüente sugestão de que qualquer grupo que não seguisse as mesmas práticas não seriam "verdadeiros ciganos". (Acton, 1974, p. 3)

Dessa forma, a mesma fusão discursiva e a prática que condenaram os ciganos à exclusão social tornam-se também a força motivadora de um essencialismo exacerbado que condena a diversidade de uma tradi- 
ção cultural à unidade imposta. Assim, apenas os ciganos que utilizassem a "língua vlax romani" - ou o romani falado pelos ciganos Roma - e mantivessem determinadas instituiçōes tradicionais, como a Kris romani (espécie de tribunal de anciãos) ou o nomadismo, por exemplo, passaram a ser considerados verdadeiros ciganos.

Essa falsa idéia, ou melhor, esses preconceitos baseados em determinadas representaçôes sobre os ciganos, segundo Acton, na maior parte das vezes eram propagados pelos próprios ciganos, ${ }^{16}$ pelos pesquisadores acadêmicos e pelas autoridades públicas responsáveis pelas políticas sociais.

A conseqüência, como em outras épocas, foi a implementação de políticas anticiganas devastadoras na Inglaterra, nas décadas de 1960 e 1970. Para o governo inglês, assim como para outros governos europeus baseados nessas idéias, apenas aqueles indivíduos que possuíssem o status de "ciganos puros ou verdadeiros" teriam os direitos e as garantias reservados às minorias étnicas. Em outras palavras, os milhares de ciganos ingleses, adaptados há séculos em algumas cidades ou regióes, passaram a ser tratados como marginais sociais, e não mais como minorias étnicas, a partir do momento em que deixaram de ser reconhecidos como ciganos.

Os chamados policy-makers, assistentes sociais, oficiais de justiça e legisladores, passaram a atuar sobre as representaçôes dos chamados "ciganos puros", isto é, nômades, exclusivamente descendentes de ciganos, praticantes da língua romani, além de outras características exóticas como as vestimentas coloridas, as danças e outros costumes.

Como afirma Acton (id., p. 54), "em algumas ocasiōes, as autoridades locais e os próprios ciganos produziram, por diferentes razōes ideológicas, mitos coincidentes sobre o verdadeiro cigano, que acabaram confundindo os acadêmicos, observadores [...]" e, principalmente, as autoridades públicas com suas políticas inconseqüentes. 
Dimitri Fazito. A identidade cigana e o efeito de “nomeaçāo”...

A caracterização da "ciganidade" no mito do nomadismo é exemplar, pois nos mostra o complexo processo de construção da identidade cigana. Isto é, nas representações sobre o cigano e em sua tradição cultural, nas quais o nomadismo aparece como símbolo determinante e atuante, não podemos deixar de notar as ambigüidades e imprecisões das quais esse termo se alimenta.

Ora o nomadismo se apresenta como uma instituição cultural - como a família ou a religião - ora se transforma em atributo e, como qualquer traço cultural, torna-se um artefato catalogável, observável e manipulável, como as vestimentas que o cigano carrega consigo. Ainda nesse oceano de nomes e significados, muitas vezes o nomadismo é identificado como uma ideologia, como atributo genético (instinto) ou como "estado de espirito" (Liégeois, 1988).

O senso comum e a ciganologia freqüentemente definem o cigano como um indivíduo nômade. Para alguns, o nomadismo seria uma instituição cultural, já que esse fato não pode ser dissociado da cultura cigana sob pena de descaracterizá-la totalmente.

Ciganólogos, como o francês Vaux de Folêtier, afirmam que "o termo nômade é quase sinônimo de bohémien [o cigano francês] tanto na linguagem cotidiana quanto na literatura. [...] As andanças são apresentadas como o efeito de uma maldição antiga, e o cigano é comparado a um judeu errante. [...] Mas a verdadeira vida dos ciganos é a viagem em família ou em grandes companhias" (Vaux de Folêtier, 1983, p. 43, grifos meus).

Os ciganos seriam "nômades por natureza", e aqueles que levam uma vida sedentária deveriam se constituir em "ciganos degenerados", "falsos ciganos" ou "menos ciganos" - para o senso comum, em geral, ser cigano é ser nômade, e aqueles sedentários são vistos como "assimilados", tanto quanto a visão sobre os indígenas brasileiros das áreas urbanas. 
Por essa mesma perspectiva, o nomadismo é definido como "instinto", algo que existe no sangue. Jean Paul Clébert (1963) ilustra bem o processo de domesticação da identidade cigana pelo senso comum ao sugerir que esses indivíduos teriam sido sempre nômades, uma característica (cultural, mas...) natural(izada) da identidade cigana.

Porém, se de um lado o nomadismo cigano se associa diretamente à perspectiva biológica configuradora de uma "raça cigana" (como parece ser o caso do senso comum em geral), de outro, por vezes, as representações sobre o nomadismo se ligam a aspectos mais estruturais das situações de contato interétnico, a exemplo da chamada travelling ideology (uma espécie de "ideologia dos viajantes"), descrita pela antropóloga Judith Okely (1983, pp. 125-31).

Neste caso, a imagem do cigano nômade e o nomadismo são compreendidos como aspectos de uma ideologia difundida universalmente pelos próprios ciganos. A travelling ideology parece associar o nomadismo a uma representação coletiva elaborada pelos ciganos com o objetivo de construir sua própria identidade em oposição ao gadjo. Segundo Okely (id., p. 126), "é significante que os ciganos prefiram ser chamados de travellers [grupo nômade inglês], ${ }^{17}$ especialmente quando conversando com os gadjê".

Contudo, o nomadismo deve ser compreendido como diacrítico, no sentido dado por Fredrik Barth (1976), um demarcador de fronteiras que se define num campo de comunicação e interação, cujo sentido se remete às tensões existentes nas relações entre ciganos e gadjé, numa primeira e ampla dimensão, e aos contrastes operativos, numa segunda dimensão interna e incorporada do sistema intra-étnico.

A meu ver, mais que a expressão direta da ideologia nativa dos ciganos, o nomadismo opera como símbolo inscrito em um campo de forças em que as relaçóes assimétricas hierarquizadas, interna e externamen- 
Dimitri Fazito. A identidade Cigana E O EFeito de “nomeaÇÃo”...

te, entre ciganos e gadjé configuram uma teia de discursos mitológicocientíficos e práticas sociais responsáveis pela justificação e legitimidade dos posicionamentos e discriminações.

Assim, avançando a proposta original de Barth, nas relações inter e intra-étnicas do universo cigano, o nomadismo deveria ser entendido como o efeito da nomeação deflagrada nas situações históricas de contato, em que as representações coletivas elaboradas ao longo das interações no campo de forças sociais, especialmente entre ciganos e gadjé, objetivam-se em estereótipos, emblemas, categorias, ações e sentimentos (Bourdieu, 2003).

É nesse sentido que o nomadismo, num segundo momento, assume a condição de representação simbólica "fundadora" das relações (de dominação) entre ciganos e gadjé - porque o "mito de origem”, a errância, torna-se prática cotidiana e se inscreve também no corpo das pessoas -, legitima-se como "artefato cultural" e reforça a diferença - e agora reforça também os discursos e as práticas sociais excludentes.

A história do nomadismo cigano parece mais uma história de terror, torturas e perseguiçóes sofridas por esses grupos marginalizados, constantemente segregados e expulsos das terras por onde passam. Não surpreende um "sentimento inato" para a peregrinação e as andanças, a marca está no corpo. $\mathrm{O}$ problema talvez esteja em querer encontrar no nomadismo uma "condição essencial" para a construção da identidade cigana, legitimando essa crença por meio de um discurso científico (ciganologia) que possibilita a perpetuação de práticas discriminatórias e racistas.

Esse parece ser o efeito mais perverso do ato de nomeação de uma rica tradição cultural fundada na diversidade e condenada a sobreviver nos interstícios das sociedades, na liminaridade perene (Bhabha, 1998). De uma ótica relacional, torna-se evidente que a tradição cultural cigana não se reduz a essencialismos de qualquer natureza, pois a diversi- 
dade inerente aos arranjos intra-étnicos, fundamentados nas relações espacializadas do parentesco e da política étnica, sugere a existência de uma comunidade sui generis - que seria atualmente definida como transnacional, mesmo que apenas imaginada (Fazito, 2000).

Finalmente, numa perspectiva mais fenomenológica sobre a identidade dos ciganos, o nomadismo é considerado um "estado de espírito" experimentado de maneira única, como algo que está além dos fatos mais concretos da vida material e que não se exprime completamente pelas ações propriamente caracterizadas da migração, pelos deslocamentos constantes e pelas viagens infindáveis. Pois,

assim como os sedentários, ainda que estes viajem, não deixam de ser sedentários, também os ciganos, ainda que não viajem, não deixam de ser nômades. Por isso é preferível falar de ciganos sedentarizados do que sedentários, já que o primeiro termo indica uma etapa provisória para pessoas cujo movimento continua sendo importante. $\mathrm{O}$ nomadismo é mais um estado de espírito do que um estado de fato. (Liégeois, 1988, p. 52)

A despeito de uma definição mais profunda, conferindo maior relevância à "autodeterminação cigana" e a seus aspectos mais simbólicos, a noção do nomadismo como estado de espírito ainda contribui para uma representação equivocada da realidade cigana. Aqui, o nomadismo é concebido universalmente como símbolo evocado e pertencente a todos os ciganos. Porém, para Liègeois (1988), esse nomadismo ainda remete ao deslocamento no espaço físico, e não a seu aspecto simbólico, ou seja, o deslocamento no espaço social, definido como projeto coletivo - este aspecto, sim, constitutivo da condição cigana (Sayad, 1998).

Além disso, Liégeois parece relegar a um segundo plano as tensões políticas e disputas de poder sobre o espaço social, fazendo-nos acreditar que os ciganos "sempre" vagaram por "desejo próprio", como se as 
Dimitri Fazito. A identidade cigana e o efeito de “nomeaçāo"...

constantes perseguições e ameaças à vida que sofreram ao longo da história não os obrigassem a isso.

Como afirma o intelectual e lingüista cigano Ian Hancock,

tem sido demonstrado que a mobilidade da população romani foi o resultado de circunstâncias históricas, que na maioria dos países não deixaram outra opção aos ciganos senão as torturas e mortes, forçando as famílias ciganas a se mobilizarem em um estilo de vida nômade [e, como se não bastasse], tal mobilidade foi [então] romantizada na ficção, tornando-se o aspecto principal do estereótipo cigano. (1987, p. 130)

Muitos ciganos, na maior parte das vezes, esforçar-se-ão para passar a imagem de um Melquíades, o cigano-eterno-viajante de Cem anos de solidão, de Gabriel García Marques, corpulento e bruto, mas livre, independente e destemido.

No plano do discurso são todos nômades, pois foram "condenados por Cristo a vagar eternamente pela terra". ${ }^{18} \mathrm{Na}$ prática, encontrei em campo uma grande parte de ciganos roma - por exemplo os kalderash, considerados um dos grupos mais tradicionais - que mora no mesmo lugar há mais de 20 anos (e demonstrava sincero interesse em permanecer assim), viaja com pouca freqüência, a não ser a trabalho, por questões políticas ou visitas aos parentes mais distantes. Também o caso dos calon no Brasil reflete o caráter multifacetado do nomadismo, pois, embora tenha conhecido diferentes grupos itinerantes calon, também encontrei em campo outros tantos "sedentarizados".

Acredito, baseado no meu trabalho de campo e nos relatos de ciganos (procedentes de diferentes categorias étnicas, como kalderash, matchuaia e xhoroxhane), que as comunidades se distribuem reticularmente no território brasileiro. Isto é, os grupos se organizam em redes hierarquizadas segundo as categorias étnicas ciganas, ocupando e singu- 
larizando um espaço físico específico pela inscrição do parentesco e das políticas de etnicidade. Embora tenha presenciado casamentos entre matrizes étnicas mais distantes (como roma e calons, as duas matrizes principais no Brasil), em geral, há uma diferenciação discursiva e prática intra-étnica relacional e dinâmica. De fato, o nomadismo é também parte operativa imprescindível das negociações intra-étnicas sobre a identidade cigana.

Assim, o nomadismo é evocado em determinados contextos para reforçar ou negar a ciganidade, dependendo das posições sociais ocupadas no campo de forças. Em alguns momentos, ciganos kalderash (roma) fundamentavam sua distinção em relação aos calon quando condenavam a vida nômade, reminiscência de um passado primitivo, símbolo da vida marginal. Contudo, num instante posterior, quando de um matrimônio entre indivíduos dos dois grupos, o nomadismo foi sistematicamente evocado como representação operativa, responsável pela unidade da identidade cigana entre categorias étnicas distintas e assimetricamente posicionadas no campo social interno.

Para além das negociações identitárias intra-étnicas, penso que, para melhor compreender como o nomadismo responde ao efeito de nomeação no campo das forças sociais (especialmente entre ciganos e não-ciganos), é preciso entender o deslocamento no território como uma homologia estrutural do deslocamento no espaço social (Sayad, 1998). Somente como resultado de tal homologia fundamental, o nomadismo pode desempenhar a função de símbolo étnico capaz de representar várias formas organizacionais, conferir sentido a vários significados e inventar imagens diversas que fundamentam a unidade na diversidade.

Não por outro motivo, as representaçōes coletivas sobre o nomadismo dependem de seu "contexto de inscrição" nas estruturas homólogas do espaço físico-geográfico e social. Desse modo, tais representações dependem do teor das interaçóes entre os atores (ciganos - e suas cate- 
Dimitri Fazito. A identidade cigana e o efeito de “nomeaçāo”...

gorias étnicas - e não-ciganos), das imagens postas em jogo, das estratégias concebidas pelos atores, da apreensão dos significados. E, especialmente, dependem da forma como esses símbolos e atores irão se estabelecer dentro do campo das forças sociais - a hierarquia social, produtora e efeito da nomeação coletiva (Bourdieu, 2003).

De maneira conclusiva, pode-se dizer que o nomadismo expóe uma relação singular do cigano com o espaço, capaz de diferenciá-lo do nãocigano e mantê-lo distante do mundo não-cigano. Primeiro porque, sob o efeito de nomeação e da força das homologias dos espaços, os ciganos são impelidos a viver nos interstícios sociais e, conseqüentemente, nos limites espaciais das sociedades.

Segundo porque, devido à incorporação ritual dos contrastes ao longo dos séculos, a maneira de ser do cigano (a ciganidade) desenvolveu uma lógica prática singular que fundamenta as redes de parentesco e a política étnica conforme as homologias estruturais do espaço.

Em outras palavras, os ciganos foram capazes de reconhecer na diversidade uma unidade interna baseada nas experiências comuns de desenraizamento (seja pela força física, seja pela força simbólica). E, mais importante, tais experiências de deslocamento puderam se conectar com uma estrutura de parentesco semelhante (patrilinearidade e patrilocalidade) e uma política étnica de segmentação estrutural ${ }^{19}$ e espacial (Fazito, 2000).

Os ciganos expressam sua territorialidade como um "arquipélago de pequenos territórios", isto é, levam consigo, em seus símbolos, artefatos, instituições e sentimentos, um espaço portátil, conquistado e domesticado à sua maneira (Teixeira, 1998, pp. 60-1). Elaboram sua identidade relacionalmente e de maneira intensa, pois afirmam a semelhança com base na experiência profunda das diferenças.

Portanto, a palavra-chave para a compreensão do nomadismo é "experiência” (Turner, 1987; Barth, 1992). Para compreendermos o valor 
do deslocamento para a construção da identidade e imaginação da comunidade cigana, devemos perceber que, à maneira de um símbolo etnicizado, o nomadismo se constitui em um elemento ambíguo e pervasivo, vivenciado pelos atores em contextos específicos, onde a homologia estrutural dos espaços físico e social se concretiza nas relações assimétricas e nos discursos de ciganos e não-ciganos - enfim, o nomadismo não é uma categoria "natural" nem imutável, porém socialmente operativa e largamente performativa na construção da identidade cigana.

\section{Notas}

1 Este artigo é resultado de minha dissertação de mestrado sobre a formação da comunidade transnacional cigana (Fazito, 2000). Agradeço a Leonardo Fígoli pelas observaçóes argutas, e expresso um agradecimento especial a leitura atenta, sugestôes e críticas pertinentes do parecerista (anônimo) da revista.

2 Numa leitura possível, ao final da estória, Kublai Khan e Marco Polo seriam o mesmo sujeito existencial e reflexivo, moldado pela poética dos opostos de Calvino - o cristal e a chama (cf. Calvino, 1995; Calvino \& Barroso, 2002). Seria, assim, um sujeito inerentemente relacional em seu paradoxo e dissimulação cotidiana: civilizado e selvagem, moderno e primitivo, racional e romântico (cf. Fazito, 2005).

3 Rom/rommí (substantivos masculino e feminino, respectivamente) é o equivalente romani para "ser humano", e não necessariamente "homem"/"mulher", pois não especifica predicado biológico mas ontológico. Nesse sentido, embora os gadjé sejam homens e mulheres, reconhecidos como tais, na cosmologia roma não são referidos com o mesmo grau de humanidade (ver Fazito, 2000). Mais adiante, a "humanidade" está relacionada com a posse do romanes, simbolização ritual e performativa do caráter existencial, o ser cigano (roma).

4 Para maiores detalhes sobre essa mitoprática do nomadismo cigano, ver adiante.

5 "Vemos que, através da oposição principal entre masculino e feminino, a relação da mulher e da sexualidade governa, neste caso, esta mitologia que é o produto da combinação de fantasmas sociais e de fantasmas sexuais socialmente instruídos" (Bourdieu, 1980a, p. 24). E também com base nessas relações entre masculino e 
Dimitri Fazito. A identidade cigana e o efeito de “nomeaÇĀo”...

feminino seria configurada, em Montesquieu, a ligação da dominação doméstica com a política dos Estados.

6 Os mitos e as lendas sobre a chegada dos ciganos à Europa, e mais tarde a sua expulsão, muitas vezes revelam mais o caráter da sociedade européia da época do que propriamente o caráter da "cultura cigana". David Sibley (1981) defende que a perseguição a grupos minoritários, como os ciganos na Europa, representa a necessidade dessa sociedade projetar suas "fantasias" e seus "desejos inconscientes" em grupos marginais (outsiders), que funcionam como bodes expiatórios, objetivando a manutenção de fronteiras baseadas na própria percepção cultural. Ver também Hancock (1987, pp. 129-30).

7 Vale dizer ainda que o equivalente do Cingar italiano na França, segundo os autores, é representado pela figura paradoxal de Panurge, o antiintelectual rabelaisiano, responsável por muitas das grandes aventuras de Pantagruel.

8 Ver também, a esse respeito, Vaux de Folêtier (1983, pp. 185-8), que afirma ter sido Cervantes o primeiro propagador do estereótipo "ladrão de crianças", e para maiores referências à presença de ciganos entre escritores europeus do período romântico. Ver Teixeira (1998, pp. 62-8) para referência às representaçôes literárias do cigano no Brasil.

9 Sobre a trajetória particular desses autores e sua influência na divulgação do estereótipo cigano, ver Moonen (1996, pp. 30-7), Fraser (1995, pp. 194-7) e Willems e Lucassen (1990, pp. 34, 37 e 42).

10 Pouco tempo depois, na segunda edição de seu livro, Grellmann procurou se retratar, já que haviam descoberto a fraude das confissóes, sendo que nada podia ser afirmado sobre o canibalismo daqueles ciganos. Entretanto, o mau já havia sido feito, e até a metade do século passado ainda podia ser encontrada na literatura produzida por alguns ciganólogos, como Popp Serboianu (em Les Tsiganes, 1930), a representação de ciganos canibais.

11 Ver Willems e Lucassen (1990, p. 42), que traçam uma espécie de genealogia do pensamento ciganológico determinante para a construção e difusão dos mitos sobre os ciganos. Além de Grellmann e Borrow, Leibich (1863), Wlislocki (1890), Serboianu (1930), Block (1936), Bloch (1953) e Clébert (1961). Especialmente Leibich, Serboianu e Block contribuíram para as políticas nazistas anticiganas, preparadas na Alemanha desde o final do século XIX e aplicadas extensivamente no período da Alemanha nazista. 
12 Para uma descrição detalhada das contribuições de Borrow, ver Williems e Lucassen (1990, pp. 33-7) e Moonen (1996, pp. 34-5).

13 Ver especialmente os comentários de Michael Stewart sobre o relacionamento entre o antigo regime comunista da Hungria e os ciganos.

14 Vale lembrar que o trabalho de Lombroso sobre as tendências criminógenas dos ciganos foi inteiramente extraído das páginas de Grellmann. Para Lombroso, os ciganos "são um exemplo vivo de toda uma raça de criminosos, tendo todos os vícios e paixões de criminosos. [...] São vis, delinqüentes [...]. Cometem assassinatos a sangue frio com o objetivo de roubar, e eram originalmente suspeitos de canibalismo [...]. Essa raça, tão baixa moralmente e tão incapaz de se desenvolver cultural e intelectualmente, é uma raça que nunca desenvolverá qualquer atividade industriosa [...]" (in Hancock, 1987, p. 113).

15 Se um entre oito avos de uma pessoa fosse parcialmente cigano, era suficiente para classificá-la como cigana. No caso dos judeus, era necessário um avô entre apenas quatro. Ou seja, para as leis alemãs, 1/8 de sangue cigano bastava para condenar o indivíduo à morte, enquanto que para um judeu era necessário $1 / 4$ de sangue (cf. Hancock, 1987, p. 64).

16 Neste caso, muitas vezes eram ciganos kalderash, do grupo roma, que na Inglaterra se consideravam ciganos "puros" ou "verdadeiros", desdenhando a condição dos ciganos autóctones, que já haviam se misturado com a população local ou com os chamados travellers por meio de casamentos inter-raciais. $\mathrm{O}$ mesmo fato se repete no Brasil, com os calons sendo acusados pelos roma de serem "falsos" ciganos ou ciganos de "segunda classe". Apesar de os calons terem sido os primeiros ciganos a chegar ao Brasil, os roma se consideram mais puros por falar uma língua diferente do português e manter costumes tradicionais legitimados pela hierarquia das categorias étnicas.

17 Vale dizer que estes grupos, travellers, constituem-se principalmente de indivíduos não-ciganos, antigos moradores das áreas urbanas que adotaram um estilo de vida alternativo, morando em traillers e se deslocando em caravanas.

18 Essa é uma estória narrada pelos ciganos, dos mais novos aos mais velhos. Como no provérbio, "acima o Céu, abaixo a Terra e no meio os Ciganos".

19 A segmentação estrutural dos agrupamentos ciganos tende a seguir as linhas de parentesco que se realizam também no território por meio da organização política - de maneira muito semelhante aos Nuer (Evans-Pritchard, 1993). 


\section{Bibliografia}

ACTON, T.

1974 Gypsy Politics and Social Change, London, Routledge/Kegan Paul.

BARTH, F.

1976 Los grupos étnicos y sus fronteras, Mexico, Fundo de Cultura Econômica.

1992 “Towards Greater Naturalism in Conceptualizing Societies", in KUPER, Adam

(ed.), Conceptualizing Societies, 1.ed., London, Routledge, pp.17-33.

BHABHA, $\mathrm{H}$.

1998 O local da cultura, Coleção Humanitas, Belo Horizonte, Editora da UFMG.

BOURDIEU, P.

$1980 \mathrm{a}$

"Le Nord e Le Midi: contribution a une analyse de l'effet Montesquieu", Actes de la Recherche en Sciences Sociales, 65, nov.

1980b "Lidentité et la représentation: élèments pour une réflexion critique sur l'idée de région", Actes de la Recherche en Sciences Sociales, 65, nov.

2003 Opoder simbólico, 6.ed., São Paulo, Bertrand Brasil.

CALVINO, I.

As cidades invisiveis, São Paulo, Companhia das Letras.

CALVINO, I. \& BARROSO, I.

2002 Seis propostas para o próximo milênio: lições americanas, 3.ed., São Paulo, Companhia das Letras.

CLÉBERT, J.-P.

1963 The Gypsies, London, Harmmondsworh.

CROWE, David

1995 A History of the Gypsies of Eastern Europe and Russia, New York, St. Martin's Griffin.

DONOVAN, B.

Changing Perceptions of Social Deviance: Gypsies in Early Modern Portugal and Brazil, Jornal of Social History, vol. 26: 33-53. 
EVANS-PRITCHARD, E. E.

1993 Os Nuer, São Paulo, Perspectiva.

FAZITO, Dimitri

2000 Transnacionalismo e etnicidade: Romanesthán, nação cigana imaginada, Belo Horizonte, 212 pp., dissertação, Departamento de Sociologia e Antropologia, Universidade Federal de Minas Gerais.

2005 Reflexôes sobre os sistemas de migração internacional: proposta para uma análise estrutural dos mecanismos intermediários, Belo Horizonte, 204 pp., tese, Centro de Desenvolvimento e Planejamento Regional, Universidade Federal de Minas Gerais.

FRASER, A.

1995

The Gypsies, Blackwell, Oxford.

HANCOCK, I.

The Pariah Syndrome, Ann Harbor, Karoma Publishers.

KENRICK, D. \& PUXON, G.

1972 The Destiny of Europe's Gypsies, London, Sussex University Press.

LIÉGEOIS, J.-P.

1987 Gypsies and Travellers, 1.ed., Strasbourg, Council of Europe, Publications Section.

1988 Los gitanos, México, Fondo de Cultura Econômica.

MOONEN, F.

1996

Ciganos na Europa e no Brasil, Recife, Edição Universitária.

OKELY, J.

1983 The Traveller-Gypsies, Cambridge, Cambridge University Press.

PIASERE, L. \& CAMPIGOTTO, A.

1990 "From Margutte to Cingar: The Archeology of an Image", in SALO, M. (ed.), 100 Years of Gypsy Studies, Maryland, Gypsy Lore Society, North American Chapter. 
Dimitri Fazito. A identidade Cigana e o efeito de “nomeaÇĀo”...

PIERONI, G.

1993

"Destestáveis na metrópole e receados na Colônia", Varia Historia, Belo Horizonte, n. 12: 114-27.

SAHLINS, $\mathrm{M}$.

1990

Ilhas de história, 1.ed., Rio de Janeiro, Jorge Zahar.

SAYAD, A.

1998 A imigração ou os paradoxos da alteridade, São Paulo, Edusp.

SIBLEY, D.

1981

Outsiders in Urban Societies, Oxford, Basil Blackwell.

STEWART, $M$.

1997

The Time of The Gypsies, Oxford, Westview Press.

TEIXEIRA, R. 1998

Correrias de ciganos pelo território mineiro (1808-1903), Belo Horizonte, 225 pp., dissertação, Faculdade de Filosofia e Ciências Humanas, Universidade Federal de Minas Gerais.

TURNER, V.

1987

The Anthropology of Performance, 1.ed., New York, PAJ Publications.

VAUX DE FOLÊTIER, F.

1983 Le monde des tsiganes, 1.ed., Espaces des Hommes, Paris, Berger-Levrault.

WILLEMS, W. \& LUCASSEN, L.

1990

"The Church of Knowledge: Representation of Gypsies in Dutch Encyclopedias and Their Sources (1724-1984)", in SALO, M. (ed.), 100 Years of Gypsy Studies, Maryland, Gypsy Lore Society, North American Chapter. 
ABSTRACT: In this article I intend to show how gypsy cultural tradition has been able to arrange a dynamic and performative identity in spite of its complex diversity. I argue that the label "gypsy", actually, is a stereotype made out of collective representations experienced by individuals of different cultural traditions along centuries of contact. The nomination effect in which social actors assymetrically positioned in the contact situation inscribe and assume collective distinctions (diacritics and frontiers) seems to strengthen the notion of "unity in diversity" present in common experiences of denial, differentiation and liminality. From a relational point of view one can observe that gypsy nomadism operates as a double face representation, a result of the coalition of mythological-scientific discourses and daily social practices: on one hand, nomadism is the terrifying consequence of endurable persecutions and exiles that are inscribed in individuals' body and reinforce the identity of common experience of difference; on the other, nomadism reinforces alterity when it is inscribed in the field of interethnic relationships as common collective experience of displacement in physical and social space.

KEY-WORDS: nomination, social classification, ethnicity, displacements, nomadism, gypsies.

Aceito em dezembro de 2006. 